\section{LEARNING FROM MISTAKES - AND TRIUMPHS}

News out of Africa is often bad, and certainly the HIV pandemic at present ravaging this continent must rate as one of the worst disasters of all time. However, even in the face of this disaster there have been glimmers of hope emanating out of this continent and other developing countries.

Perhaps most exciting of all are the lessons we learn from Uganda, where an intensive programme of primary school education on lifestyle choices and encouragement to delay sexual debut have resulted in a largely AIDS-free generation coming up and now contemplating marriage proud of their HIV-negative status. Indeed numbers reflect this, with under19 -year-old females having less than 1\% HIV prevalence in a recent UNAIDS report. Similarly, programmes launched in Zambia have had good effect and sentinel surveys in Lusaka show that the percentage of pregnant girls aged 15 - 19 infected with HIV has on average dropped by almost half in the last 6 years.

Senegal is another African country that can teach some lessons. President Abdoulaye Wade attributes his country's successful campaign against AIDS to his government's early response to the disease; its mobilisation of the community in the fight against it, and its investment in research. Senegal began tackling HIV/AIDS in 1986 when the first 6 cases were detected and became one of the first countries to develop a national AIDS council. By 1987, it had a national blood screening programme to ensure safe blood transfusions. In a recent interview, Wade states that all population groups were mobilised - the youth, women, and especially religions. These played a very important role; $95 \%$ of the population is Muslim and $5 \%$ are Christian, and both were involved in the struggle. He goes on to say that although the Christians may not have accepted the use of condoms, they are working well for protection against HIV. The country's Muslims, many of whom practise polygamy, also do not condone the use of condoms: they have therefore decided that the most important factor is prevention through abstinence. At the end of 1999, the estimated HIV prevalence in Senegal was $1.8 \%$ among the adult population.

Mocambique, on the other hand, has in recent years put much effort into its sexually transmitted disease prevention and treatment programmes, with good effect. This has paid dividends in the HIV epidemic, since we know that genital ulcer disease is a very important factor in efficient HIV transmission.

Among other developing countries, Thailand stands out as having curbed a rampant heterosexual epidemic by ensuring $100 \%$ condom use by commercial sex workers and general education of the male population. Other routes of transmission have unfortunately assumed greater importance, such as sharing of intravenous drug injecting equipment and unprotected sex between men.

In Brazil, where over half a million adults are living with HIV, the government has taken an active lead in HIV prevention, care and protection of the rights of people affected by the epidemic. Perhaps the most visible commitment is the government's undertaking to provide free antiretroviral therapy to all those who need it. Actively engaging non-governmental organisations, the Brazilian government has sought to reach the general as well as the marginalised public in information campaigns and prevention services. A recent survey conducted in Brazil showed that while less than $5 \%$ of young men in 1989 reported using a condom the first time they had sex, the figure in 1999 was close to $50 \%$ - a tenfold increase, borne out by the massive rise in sales of commercial condoms from 70 million a year in 1993 to 320 million a year in 1999 !

In our own country I am hugely excited by the Lovelife 
Campaign, which I see spilling into the media and making its presence felt on billboards and in townships. I have as yet not seen any evaluation of efficacy, but I imagine that this is just the kind of upfront and contemporary message that much of our South African youth could relate to.

What remains unfathomable to me is how easily we South Africans miss opportunities to engage and move forward constructively. Recently the Catholic bishops came under a great deal of criticism for negating the use of condoms by the Catholic community as a valid method of protection against HIV. As I see it, both the critics and the bishops are partially right and partially wrong. The tragedy in the whole debacle is that neither group seems to have realised that the epidemic is occurring in a heterogeneous and vastly diverse population, which cannot be regarded as one population when finding preventive strategies. It is clear that there are high-risk groups, namely sex workers, where the condom message is not only important but probably life-saving. In this group I would advocate 100\% condom use and sound information about consequences for not doing so. Conversely, in the as yet sexually uninitiated I would think that a message of abstinence (couched in as funky and hip-hop terms as are necessary to be age-acceptable) is both wise and reasonable, but again sound information should be provided about consequences and alternatives. Everyone else falls into the spectrum between, depending on their risk stratification. In Brazil, for example, it was shown in 1999 that men were more likely to use condoms in their more risky partnerships than with wives or long-term partners.

There is no doubt that we must learn from the mistakes of others, but we can also learn from their triumphs. Uganda and Zambia have somehow found ways to safeguard the AIDS-free generation in their countries by empowering them with opportunities for lifestyle choices and we should put most of our energy into doing the same. Our AIDS-free generation is precious. Yet there are those who, by choice of profession or recreation, place themselves at risk, and they need the condom message. Finally, a vast number of South Africans are beyond prevention strategy and are in need of antiretroviral therapy. In this regard Brazil has shown what can be done in a developing country, but South Africa still has the opportunity to show what an African country can do.

\section{LINDA-GAIL BEKKER}

Managing Editor

\section{O N F E R E N C E N O T I C E}

The Biennial Joint Conference of Southern African Sexually Transmitted Diseases, Infectious Diseases and HIV Clinicians Societies is to be held from 2 to 6 December 2001 at the Music Conservatoire, Stellenbosch, Western Cape. Collectively the conference will cover a comprehensive array of medical challenges facing subSaharan Africa - tuberculosis, malaria, sexually transmitted diseases, pertussis, small pox, typhoid, cholera, yellow fever, diarrhoeal disease, infection control and most matters related to HIV/AIDS.
HIV will feature throughout the meeting with the last day focusing on practical, clinical, community and ethical issues in HIV management for doctors and primary care professional practitioners. An update with final details of the planned programme will be available shortly.

For further information contact the congress secretariat: Sune van Rooyen or Liezel Horn at the Faculty of Medicine, PO Box 19063, Tygerberg, 7505.
Sunè van Rooyen
Liezèl Horn
Tel: 0219389245
Tel: +270219389238
Fax: +270219332649
Fax: +270219332649
E-mail:
E-mail:
sunevr@maties.sun.ac.za
LH@maties.sun.ac.za 